\title{
Creating of structure of facts for the knowledge base of an expert system for wind power plant's equipment diagnosis
}

\author{
Stanisław Duer ${ }^{1, *}$, Paweł Wrzesień ${ }^{2}$, and Radosław Duer ${ }^{3}$ \\ ${ }^{1}$ Technical University of Koszalin, Department of Mechanics, 15-17 Raclawicka St., 75-620 Koszalin, Poland \\ ${ }^{2}$ Vortex Energy Polska sp. z o.o., ul. Malczewskiego 26, 71-612 Szczecin, Poland \\ ${ }^{3}$ Technical University of Koszalin, Department of Electronics and Informatics, 2 Śniadeckich St., 75-453 Koszalin, Poland
}

\begin{abstract}
This article describes rules and conditions for making a structure (a set) of facts for an expert knowledge base of the intelligent system to diagnose Wind Power Plants' equipment. Considering particular operational conditions of a technical object, that is a set of Wind Power Plant's equipment, this is a significant issue. A structural model of Wind Power Plant's equipment is developed. Based on that, a functional - diagnostic model of Wind Power Plant's equipment is elaborated. That model is a basis for determining primary elements of the object structure, as well as for interpreting a set of diagnostic signals and their reference signals. The key content of this paper is a description of rules for building of facts on the basis of developed analytical dependence. According to facts, their dependence is described by rules for transferring of a set of pieces of diagnostic information into a specific set of facts. The article consists of four chapters that concern particular issues on the subject.
\end{abstract}

\section{Introduction}

Expert systems are programs that can help or replace human experts in a specific field. Such systems can provide pieces of advice, recommendations or diagnoses relating to problems appearing in a specific field. Computer programs developed in that way are of great importance and use for fields that are poorly formalized (without having mathematical backgrounds, which could be created algorithms for) e.g. diagnostics, medicine, etc. Expert systems are characterized not only by their capability to solve non-algorithmically defined problems but also have other advantages e.g. collected expert knowledge can be easily transmitted and available if experts are not present at time (due to their sick health or retirement) and coded knowledge can be easily delivered (it is easier to copy a computer program than teach another human) and a response can be acquired fast, and there are no human symptoms like fatigue nor stress.

In literature, supporting and intelligent systems are presented in detail. Such systems are used for supervision or organization of technical - technological problems in terms of their diagnosis and quality evaluation. Those systems are particularly useful when a number of variables are analyzed and it is required to consider complex factors having influence on those variables relating to: a technical condition of technical equipment, tools, manufacturing means, or selection of conditions and parameters of processes. Important achievements are brought by works of B. Buchannan, E. Shortliffe, W. Kacalak, and others [1-13]. Those works help to build up a set of conclusion rules, create knowledge representation, knowledge collection and analysis. Their works considerably help to practically solve those problems when creating expert knowledge, including its application in diagnostics or operation of technical equipment. There should be also considered works by F. Hayer-Roth, D. Waterman and others in this issue since their works [4,5,14-19] cover mathematical background in terms of development and organization of expert systems, including rules for creation of expert knowledge bases, creation of conclusion rules and means of their analyses (look through and sort out).

The paper by F. Hayer-Roth, D. Waterman, D. Lenat $[5,19]$ included descriptive and mathematical grounds for designing of expert systems. The rules are quite well developed for the creation of an expert database including a set of inference rules and ways of their analysis (review and sorting).

In papers of M. Białko, W. Kacalak, W. Pedrycz and others $[2,5-8,10,15,19,20]$, presented a wide approach to the issue of neural networks, machine teaching of neural networks, genetic algorithms as well as sets and fuzzy knowledge. The paper includes well-developed issues of machine teaching and training of neural networks. Such problems were solved as the following: an introduction to neural networks, teaching of layered neural networks as well as teaching through competition between neurons in a network. The paper also solves in a good manner the problems of the construction and functioning of genetic algorithms. The paper covers extensively fuzzy knowledge systems, ways to represent this knowledge and to use it in the organization of artificial neural networks and expert systems. 
The papers by (L. Będkowski, T. Dąbrowski, A. Rosiński and L. Pokoradi, [1, 16-18] presents the theoretical background of the reliability of technical devices in the operation process. The author presented mathematical basis of the policy rules of the organization of repairs (replacement of components (constructional elements)) of devices. Another important practical problem which was solved in the study is the representation of the ways and methods to set periods of repairs (replacements of functional parts) of devices and their optimization. The paper also covers preventative maintenance procedures including drawbacks of this type of maintenance. A large part of the paper deals with the issues of the development and verification of the maintenance policy strategy. The study is also of a large practical importance as regards the organization of the development of theoretical models of technical devices' maintenance processes as well as the conditions and rules of their modification.

The paper by (Duer 2010-2016) [4,14,20-25], makes the use more specific (and improved) of the results of diagnostic testing in the organization of a technical object's maintenance system. The paper presents the mechanism of a negative change of states in a technical object, as a result of which there occurs in the object a reduction of its operational properties: a change of the state. The author also presented a diagram and a description of artificial neural network structures and mathematical dependencies which express the idea of the functioning of the network in compliance with the algorithm developed for it. The paper also presents theoretical grounds for diagnosing of technical objects in trivalent logic with the use of an artificial neural network. The results of the study were supported with an example of a diagnostic information database for the device tested.

This paper aims at developing a set of rules for a knowledge base of the expert system that will allow identifying defects of the object under examination.

\section{Functional - diagnostic structure of wind power plant's equipment}

Wind Power Plants (WPPs) can be divided into two types in terms of localization, that is onshore and offshore (WPPs). Onshore (WPPs) are usually characterized by irregular localization of particular Wind Turbine Generators (WTGs) due to topographical conditions [4, 20, 24] (Fig. 1). On the other hand, offshore (WPPs) are characterized by a regular localization structure of particular (WTGs). For offshore, is used (DC) connection into the land. Onshore (WPPs) feed the grid by means of (MV) or (HV) power transformers. Fig. 1 shows a structure of an onshore (WPP), which consists of three (WTGs) connected by means of MV step-up power transformers and (MV) cable lines into the (HV) Substation that is used to output power into the National Distribution System by (HV) power line at the Point of Common Coupling (PCC) [4, $5,13,20]$.
A functional structure of the (WPP) was created (Fig. 1) for a developed system for supervision and safety usage of a wind power plant. A designed knowledge base relates to the (WPP) consisting of five (5) unit (WTGs) of type Vestas V90 2.0 MW connected to the (HV) Substation by means of two $20-\mathrm{kV}$ cable lines, which are an internal Electrical Infrastructure of the Wind Power Plant (Fig. 1). The (WPP) was designed to be located in the north of Poland, that is to say, in the $1^{\text {st }}$ grade wind energy zone in Poland. The (HV) Substation was designed as power output into the grid [11,20-23].

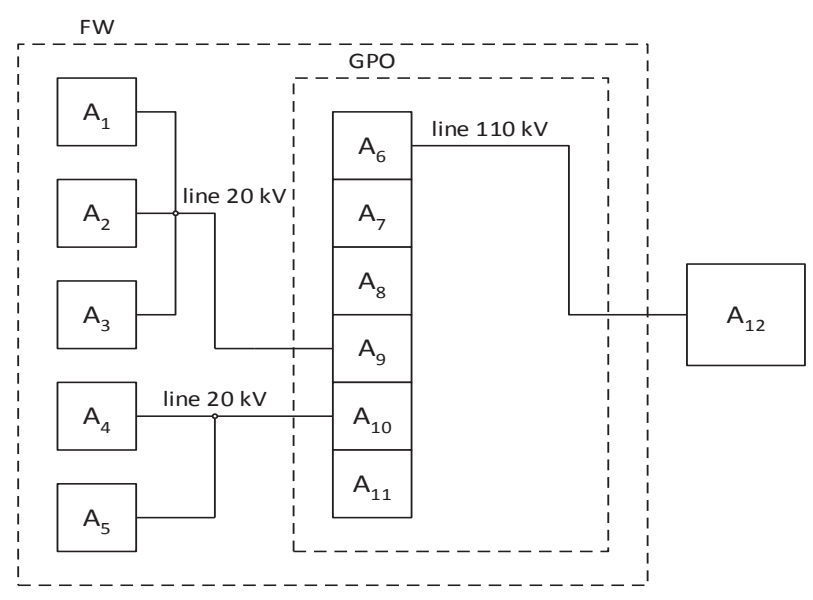

Fig. 1. Block diagram of the WPP, where: $A_{1} \div A_{5}$ : no. $1 \div 5$ - Wind Turbine Generators, $\mathrm{A}_{6}-$ Power Transformer Field, $A_{7}-$ Voltage Measurement Field, $A_{8}-$ Shunt Reactor Filed, $A_{9}-$ Line no. 1 for Wind Turbine Generators no. $1 \div 3$, $\mathrm{A}_{10}$ - Line no. 2 for Wind Turbine Generators no. $4 \div 5$, $\mathrm{A}_{11}$ - General Signalization, $\mathrm{A}_{12}$ - Point of Common Coupling, GPO - Wind Farm Substation, GPZ - Grid Operator's Substation, FW - Wind Power Plant, PCC - Point of Common Coupling.

The Wind Farm Substation is connected into the Grid Operator's Substation at the (PCC) by means of a (HV) cable power line. A $20 / 110-\mathrm{kV}$ power transformer is fed by two $20-\mathrm{kV}$ cable power lines connected to (WTGs) (Fig. 2). The issue concerning creating of expert knowledge bases is a specialized field of science that relates to development of methods and construction principles, and organization of sets of pieces of engineering, diagnostic and operational expertise information on a specific technical and complex object under examination. A basis to create a set of engineering knowledge on a specific object under examination is knowledge, which is possessed by a user of the specific object in terms of its construction, usage and operation. Engineering knowledge on the specific object is constantly provided with (expanded) diagnostic data of the object determined by diagnostic evaluations.

A diagnostic evaluation of the technical object is an analytical - creative process for acquiring sets of pieces of diagnostic information on a specific object.

A set of pieces of diagnostic information that is determined through that process consists of sub-sets of pieces of information on: making of a functional - 


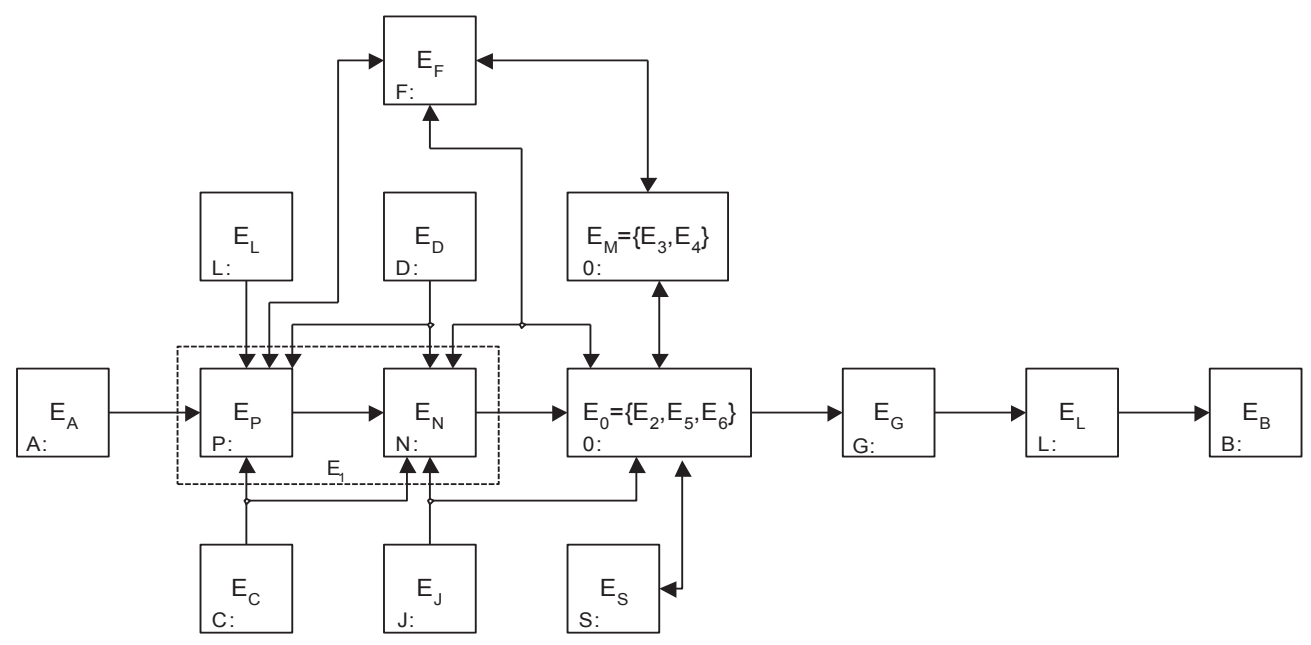

Fig. 2. Functional - diagnostic diagram of the Wind Power Plant's equipment, where: A - Environmental and Ambient, B - Grid, C - Brake Systems, D - Hydraulics, E - Yaw System, F - Communications, G - Connectors, H - Protection Relays, I - Pitch System, J - Cooling and Heating Systems, K - Transmission, L - MV Unit Power Transformer, $\mathrm{M}$ - Controller, $\mathrm{N}$ - Gearbox, $\mathrm{O}$ - Generator, $\mathrm{P}$ - Rotor.

diagnostic model, determining of a sub-set of basic elements, determining of a sub-set of diagnostic signals and their reference signals (Fig. 2).

To make diagnostic evaluation of the technical object, it requires possessing diagnostic and engineering knowledge on construction, operation, and diagnosis of such technical objects [11,20-23]

This section presents information by its stages due to a multilevel way of transformation of information on the object into a form of an expert knowledge. Stage 1 is a presentation of a fundamental theory relating to functioning and operation of (WTG) and (WPP's) equipment. Stage 2 is a description of issues relating to diagnostic evaluation of the examined equipment. As a result of this approach, engineering and diagnostic knowledge on (WTG) and (WPP's) equipment is acquired. Issues relating to creation of expert knowledge bases will be presented in the next section (Fig. 2).

A basis to carry out diagnostic research on technical equipment is functional - diagnostic models of such objects [4-10]. Thus, a functional - diagnostic model of the (WPP) was developed (Fig. 2 and Table 1).

Table 1. Internal structure of the Wind Power Plant model.

\begin{tabular}{|c|c|c|c|c|c|}
\hline $\begin{array}{c}\text { Object's } \\
\text { units }\end{array}$ & \multicolumn{6}{|c|}{$\begin{array}{c}\text { Fundamental elements }\left\{\mathrm{e}_{\mathrm{i}, \mathrm{j}}\right\} \\
\text { in the Wind Power Plant } \\
\text { model }\end{array}$} \\
\hline $\mathrm{E}_{1}$ & $\mathrm{e}_{1,1}$ & $\mathrm{e}_{1,2}$ & $\mathrm{e}_{1,3}$ & $\mathrm{e}_{1,4}$ & $\mathrm{e}_{1,5}$ \\
\hline $\mathrm{E}_{2}$ & $\mathrm{e}_{2,1}$ & $\mathrm{e}_{2,2}$ & $\varnothing$ & $\varnothing$ & $\varnothing$ \\
\hline $\mathrm{E}_{3}$ & $\mathrm{e}_{3,1}$ & $\mathrm{e}_{3,2}$ & $\mathrm{e}_{3,3}$ & $\varnothing$ & $\varnothing$ \\
\hline $\mathrm{E}_{4}$ & $\mathrm{e}_{4,1}$ & $\mathrm{e}_{4,2}$ & $\varnothing$ & $\varnothing$ & $\varnothing$ \\
\hline $\mathrm{E}_{5}$ & $\mathrm{e}_{5,1}$ & $\mathrm{e}_{5,2}$ & $\varnothing$ & $\varnothing$ & $\varnothing$ \\
\hline $\mathrm{E}_{6}$ & $\mathrm{e}_{6,1}$ & $\mathrm{e}_{6,2}$ & $\varnothing$ & $\varnothing$ & $\varnothing$ \\
\hline $\mathrm{E}_{7}$ & $\mathrm{e}_{7,1}$ & $\varnothing$ & $\varnothing$ & $\varnothing$ & $\varnothing$ \\
\hline
\end{tabular}

where:

$\mathrm{e}_{1,1}, \mathrm{e}_{1,2}, \mathrm{e}_{1,3}, \mathrm{e}_{1,4}, \mathrm{e}_{1,5}-$ Wind Turbine Generators no. $1 \div 5, \mathrm{e}_{2,1}$, $\mathrm{e}_{2,2}-\mathrm{MV}$ cable power lines no. $1 \& 2, \mathrm{e}_{3,1} \div \mathrm{e}_{3,3}-\mathrm{MV}$ switchgear no. $1 \div 3, \mathrm{e}_{4,1}-\mathrm{a}$ measurement and diagnostic system of electrical parameters in specific elements of the wind power plant, $\mathrm{e}_{4,2}$ - a diagnostic system of the wind power plant, $\mathrm{e}_{5,1}-\mathrm{a}$ shunt reactor of the wind power plant $\mathrm{e}_{5,2}-$ an auxiliary power transformer of the wind power plant, $\mathrm{e}_{6,1}-\mathrm{HV}$ power transformer, $\mathrm{e}_{6,2}-\mathrm{HV}$ Switchgear, $\mathrm{e}_{7,1}-$ Substation.

As a result of the functional - diagnostic evaluation, seven $i$ - functional sets were determined in the wind power plant model. A sub-set of $\mathrm{j}$-fundamental (functional) elements was determined in each i-set. A determined set of fundamental elements $\left\{\mathrm{e}_{\mathrm{i}, \mathrm{j}}\right\}$ in the wind power plant model, which determines its internal structure, is shown in the table 1.

The developed functional - diagnostic model of the Wind Power Plant shown in Fig. 2 was also a basis to determine a set of diagnostic signals, as well as their reference signals. The determined set of diagnostic signals $\left\{\mathrm{X}\left(\mathrm{e}_{\mathrm{i}, \mathrm{j}}\right)\right\}$ is shown in the Table 2 .

Table 2. Set of diagnostic signals for an object.

\begin{tabular}{|c|c|c|c|c|c|}
\hline $\begin{array}{c}\text { Object's } \\
\text { units }\end{array}$ & \multicolumn{5}{|c|}{ Set of diagnostic signals in the Wind Power } \\
\hline $\mathrm{E}_{1}$ & $\mathrm{X}\left(\mathrm{e}_{1,1}\right)$ & $\mathrm{X}\left(\mathrm{e}_{1,2}\right)$ & $\mathrm{X}\left(\mathrm{e}_{1,3}\right)$ & $\mathrm{X}\left(\mathrm{e}_{1,4}\right)$ & $\mathrm{X}\left(\mathrm{e}_{1,5}\right)$ \\
\hline $\mathrm{E}_{2}$ & $\mathrm{X}\left(\mathrm{e}_{2,1}\right)$ & $\mathrm{X}\left(\mathrm{e}_{2,2}\right)$ & $\varnothing$ & $\varnothing$ & $\varnothing$ \\
\hline $\mathrm{E}_{3}$ & $\mathrm{X}\left(\mathrm{e}_{3,1}\right)$ & $\mathrm{X}\left(\mathrm{e}_{3,2}\right)$ & $\mathrm{X}\left(\mathrm{e}_{3,3}\right)$ & $\varnothing$ & $\varnothing$ \\
\hline $\mathrm{E}_{4}$ & $\mathrm{X}\left(\mathrm{e}_{4,1}\right)$ & $\mathrm{X}\left(\mathrm{e}_{4,2}\right)$ & $\varnothing$ & $\varnothing$ & $\varnothing$ \\
\hline $\mathrm{E}_{5}$ & $\mathrm{X}\left(\mathrm{e}_{5,1}\right)$ & $\mathrm{X}\left(\mathrm{e}_{5,2}\right)$ & $\varnothing$ & $\varnothing$ & $\varnothing$ \\
\hline $\mathrm{E}_{6}$ & $\mathrm{X}\left(\mathrm{e}_{6,1}\right)$ & $\mathrm{X}\left(\mathrm{e}_{6,2}\right)$ & $\varnothing$ & $\varnothing$ & $\varnothing$ \\
\hline $\mathrm{E}_{7}$ & $\mathrm{X}\left(\mathrm{e}_{7,1}\right)$ & $\varnothing$ & $\varnothing$ & $\varnothing$ & $\varnothing$ \\
\hline
\end{tabular}

An effective measurement and registry system for a set of diagnostic measuring signals of a wind turbine generator $\left\{\mathrm{X}\left(\mathrm{e}_{\mathrm{i}, \mathrm{j}}\right)\right\}$ is designated by means of a diagnostic model of the object (see Fig. 2). Example measurement values of diagnostic signals of a wind turbine generator and a power transformer of the specific electrical substation are presented in Fig. 3.

By analyzing values of measurement signals, a set of reference diagnostic signals $\left\{\mathrm{X}_{\mathrm{w}}\left(\mathrm{e}_{\mathrm{i}, \mathrm{j}}\right)\right\}$ of wind turbine generators is designated and shown in Table 3. 


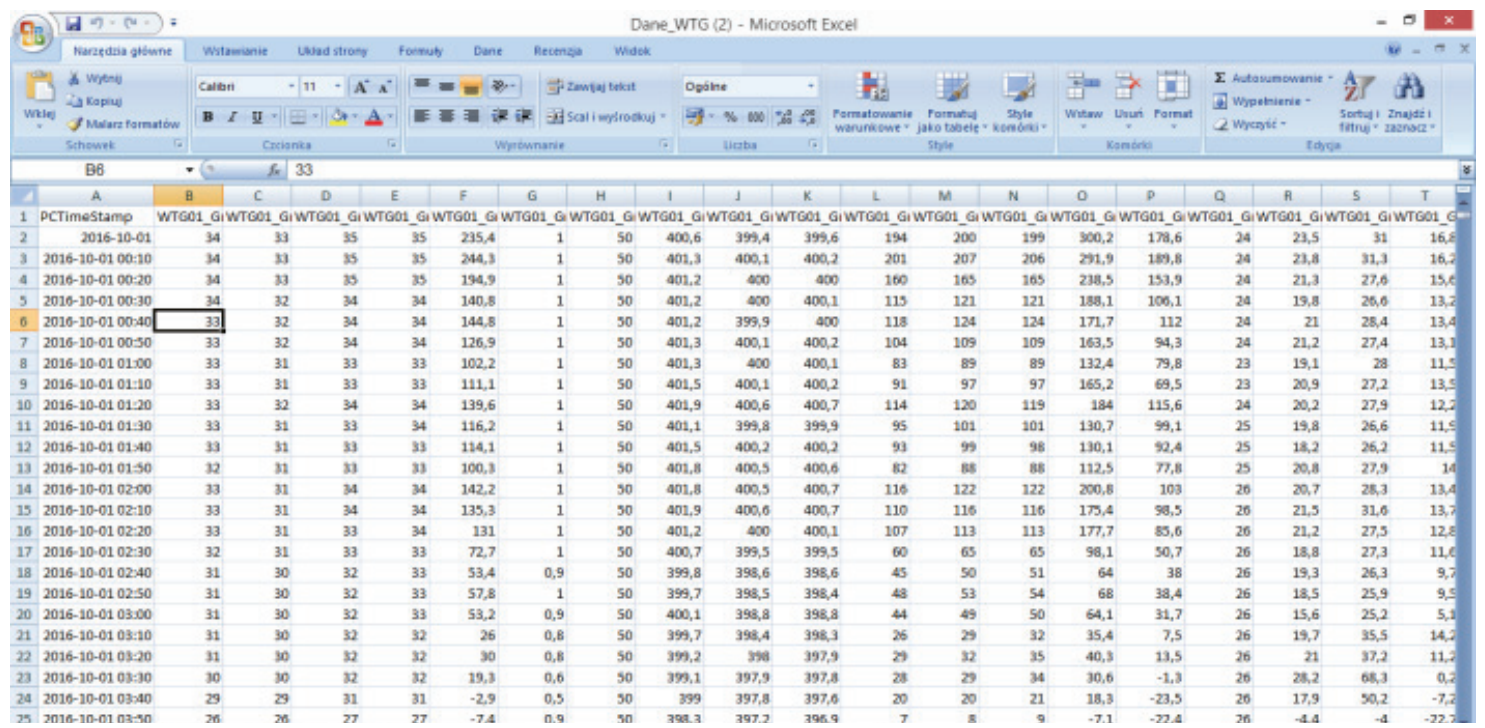

Fig. 3. Measurement values from a wind turbine generator.

Table 3. Set of measurement diagnostic signals and reference signals $\left\{\mathrm{X}_{\mathrm{w}}\left(\mathrm{e}_{\mathrm{i}, \mathrm{j}}\right)\right\}$ for one wind turbine generator in a Wind Power Plant as an example.

\begin{tabular}{|c|c|c|c|}
\hline \multicolumn{2}{|c|}{ Object Units } & \multicolumn{2}{|c|}{ Signals of Basic Object Components } \\
\hline $\begin{array}{c}\text { Sym- } \\
\text { bol }\end{array}$ & Description & $\begin{array}{c}\text { Symb- } \\
\text { ol }\end{array}$ & $\begin{array}{l}\text { Description of example } \\
\text { diagnostic signals }\end{array}$ \\
\hline \multirow{5}{*}{$\mathrm{E}_{1}$} & \multirow{5}{*}{$\begin{array}{l}\text { Nacelle } \\
\text { with } \\
\text { drivetrain }\end{array}$} & $\mathrm{X}\left(\mathrm{e}_{1,1}\right)$ & $\begin{array}{l}\text { Wind speed and direction } \\
\text { measurement system } \mathbf{- 1 8} \\
\text { reference value } \mathbf{1 8}\end{array}$ \\
\hline & & $\mathrm{X}\left(\mathrm{e}_{1,2}\right)$ & $\begin{array}{lll}\begin{array}{l}\text { Yaw system } \\
\text { referencevalue 240 }\end{array} & \mathbf{2 4 0} \\
\end{array}$ \\
\hline & & $\mathrm{X}\left(\mathrm{e}_{1,3}\right)$ & $\begin{array}{llll}\begin{array}{l}\text { Drivetrain } \\
\text { value } 240\end{array} & 239 & \text { reference } \\
\end{array}$ \\
\hline & & $\mathrm{X}\left(\mathrm{e}_{1,4}\right)$ & Rotor - 57 reference value 60 \\
\hline & & $\mathrm{X}\left(\mathrm{e}_{1,5}\right)$ & $\begin{array}{l}\text { Pitch system - 12,5 reference } \\
\text { value } \mathbf{1 3}\end{array}$ \\
\hline \multirow{3}{*}{$\mathrm{E}_{2}$} & \multirow{3}{*}{ LSS } & $\mathrm{X}\left(\mathrm{e}_{2,1}\right)$ & $\begin{array}{l}\text { LSS stabilisation system - } \\
\mathbf{0 , 0 0 3 8} \text { reference value } \mathbf{0 , 0 0 3 5}\end{array}$ \\
\hline & & $\mathrm{X}\left(\mathrm{e}_{2,2}\right)$ & LSS - 746 reference value 750 \\
\hline & & $\mathrm{X}\left(\mathrm{e}_{2,3}\right)$ & $\begin{array}{l}\text { LSS grease system- } \\
\text { reference value } \mathbf{3 0}\end{array}$ \\
\hline \multirow{4}{*}{$\mathrm{E}_{3}$} & \multirow{4}{*}{ Gearbox } & $\mathrm{X}\left(\mathrm{e}_{3,1}\right)$ & $\begin{array}{l}\text { Gearbox temperature regulation } \\
\text { system - } \mathbf{3 8} \text { reference value } \mathbf{4 0}\end{array}$ \\
\hline & & $\mathrm{X}\left(\mathrm{e}_{3,2}\right)$ & $\begin{array}{l}\text { Gearbox- } 1487 \text { reference value } \\
1500\end{array}$ \\
\hline & & $\mathrm{X}\left(\mathrm{e}_{3,3}\right)$ & $\begin{array}{l}\text { Clutch - } 1487 \text { reference value } \\
\mathbf{1 5 0 0}\end{array}$ \\
\hline & & $\mathrm{X}\left(\mathrm{e}_{3,4}\right)$ & $\begin{array}{lll}\begin{array}{l}\text { Mechanical brake- } \\
\text { referencevalue } 1500\end{array} & 1487 \\
\end{array}$ \\
\hline \multirow[t]{2}{*}{$\mathrm{E}_{4}$} & \multirow[t]{2}{*}{ Generator } & $\mathrm{X}\left(\mathrm{e}_{4,1}\right)$ & $\begin{array}{l}\text { Generator } \\
\text { regulation system } \quad-\quad \mathbf{3 8} \\
\text { reference value } \mathbf{4 0}\end{array}$ \\
\hline & & $\mathrm{X}\left(\mathrm{e}_{4,2}\right)$ & $\begin{array}{l}\text { Generator- } 690 \text { reference value } \\
690\end{array}$ \\
\hline \multirow[b]{2}{*}{$\mathrm{E}_{5}$} & \multirow{2}{*}{ Magnetizer } & $\mathrm{X}\left(\mathrm{e}_{5,1}\right)$ & $\begin{array}{lll}\begin{array}{l}\text { Magnetizer- } \\
\text { value } 3,40\end{array} & \mathbf{3 , 3 5} & \text { reference } \\
\end{array}$ \\
\hline & & $\mathrm{X}\left(\mathrm{e}_{5,2}\right)$ & 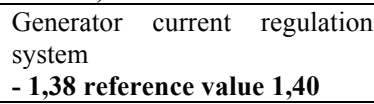 \\
\hline \multirow{2}{*}{$\mathrm{E}_{6}$} & \multirow{2}{*}{ Converter } & $\mathrm{X}\left(\mathrm{e}_{6,1}\right)$ & $\begin{array}{l}\text { Power regulator system- } \mathbf{1 , 6 7} \\
\text { reference value } \mathbf{1 , 8 0}\end{array}$ \\
\hline & & $\mathrm{X}\left(\mathrm{e}_{6,2}\right)$ & $\begin{array}{l}\text { Converter- } 678 \text { reference value } \\
690\end{array}$ \\
\hline $\mathrm{E}_{7}$ & $\begin{array}{l}\text { MV } \\
\text { Transformer }\end{array}$ & $\mathrm{X}\left(\mathrm{e}_{7,1}\right)$ & $\begin{array}{l}\text { MV transformer- } \\
\text { reference value } \mathbf{1 , 8 0}\end{array}$ \\
\hline
\end{tabular}

\section{Structure of facts in the expert knowledge base for wind power plant's equipment}

When creating a system for supervision and safety usage of the wind power plant, 306 facts were developed, that is parameters, defined in groups of elements, equipment, and units required to specify a technical and functional condition of the whole wind power plant, including wind turbine generators, (MV) equipment and networks, (HV) equipment and networks, and the substation [23]. 109 rules describing specific functional states of the wind power plant were developed on the basis of facts (parameters). Fig. 2 shows a block diagram of the wind power plant's structure in the developed expert system. Diagnostic tests on technical equipment are based on functional - diagnostic models for those objects [8-16, 19]. Thus, a functional - diagnostic model of the wind power plant (see Fig. 2) was developed for this paper. The developed model of the object under examination is a basis to determine a set of diagnostic signals and their reference signals. A functional - diagnostic diagram of the object under examination is shown in Fig. 2. As a result of the functional - diagnostic analysis, fourteen functional units were identified in the object. A sub-set of functional elements was determined in each unit and diagnostic output signals being a set of diagnostic signals $\left\{\mathrm{X}\left(\mathrm{E}_{\mathrm{i}}\right)\right\}$ were determined. Fig. 2 shows a graphical representation of the block structure of the wind power plant in the developed expert system.

Fundamental elements of the wind power plant were analyzed in order to determine facts (parameters and working units) for the wind power plant (Fig. 2). As a result of this, two fundamental functional - structure units were determined: a wind turbine generator and a substation (Fig. 2). Then, basic blocks consisting of characteristic parameters of equipment, systems and networks were determined for each functional - structure 
unit. Wind turbine generators were divided into the blocks A - P, where: A - Environmental and Ambient, B - Grid, C- Brake Systems, D - Hydraulics, E -Yaw System, F - Communications, G - Connectors, H - Protection Relays, I - Pitch System, J - Cooling and Heating Systems, K - Transmission, L - MV Unit Power Transformer, M - Controller, N - Gearbox, O Generator, P-Rotor.

Facts for the Substation were categorized into the Blocks Q-W, where: R- Feeder Cable Line Field, R - Shunt Reactor Filed, S - Power Transformer Field, T - Auxiliaries Field, U - Voltage Measurement Field, W- General Signalization.

Each block of facts for wind turbine generators and the substation (Fig. 2) consists of several parameters, where an exact number of parameters depends on specific functions and a number of equipment in a specific block [4]. The Block A- Environmental and Ambient consists of 12 parameters, including 3 parameters PA010, PA011, and PA012 defined as reserve and without any assigned values / characteristics in order to ensure a possibility for future expanding the expert system if necessary. The Block A- Environmental and Ambient consists of the following facts:

- Cut $_{\text {in }}$ wind speed,

- Wind speed for WTG ready,

- Wind speed for WTG nominal power,

- Wind speed for WTG non-nominal power,

- $\quad$ Cut $_{\text {out }}$ wind speed,

- Wind speed for WTG survive conditions,

- Wind direction,

- Ambient temperature,

- Air pressure,

- Reserve.
Threaten (13) defining categories were developed in order to identify characteristics of facts (parameters) as follows (Fig. 4):

1. Object: specifies place assigned to a specific fact e.g. wind turbine generator or substation.

2. Voltage: specifies voltage assigned to a specific fact e.g. $20-\mathrm{kV}$ or $110-\mathrm{kV}$.

3. Direction: where signals come from e.g. WTG or substation.

4. Block: specifies a group which a specific fact was assigned to, e.g. Block A.

5. Field: specifies a field in the MV switching room, which a specific fact is assigned to, e.g. feeder cable line field.

6. Type: specifies a type of a specific fact e.g. measurement or states.

7. Symbol: all parameters (facts and rules) have their own symbol, which is made as follows:

$$
\text { for: } X=(P \text { or } R) \rightarrow \text { If Yes } Y \text { then } Z Z Z
$$

where:

$X-$ specifies a parameter's type: $X=(P$ or $R)$, $\mathrm{P}$ - facts, $\mathrm{R}$ - rules, $\mathrm{Y}$ - specifies a specific block, where: $\mathrm{Y}=\mathrm{A}$ (where: A - Environment and Ambient) or B etc., $\mathrm{ZZZ}$ - three digit number assigned to a specific parameter.

8. $\boldsymbol{A} \boldsymbol{b} \boldsymbol{b} .:$ a letter abbreviation is assigned to all parameters of the system in order to make identification easier;

9. Default: default value;

10. Minimum: min. values are determined for facts;

11. Maximum: max. values are determined for facts;

12. Unit: measurement units are given for each fact;

13. State: state 0 or state 1 for two-bit facts.

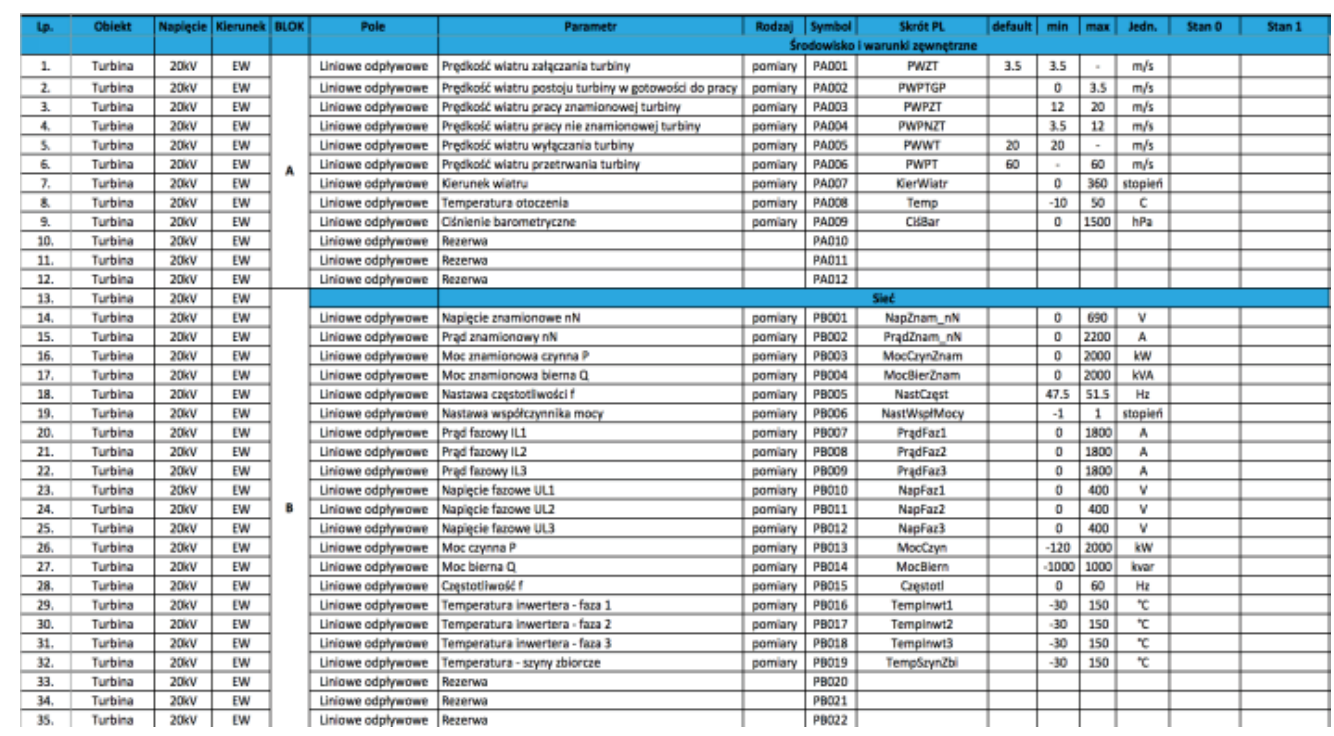

Fig. 4. Table of the Facts for the Block A - Environment and Ambient and the Block B - Grid (example).

Interpretation of dependence (1). If a fact or a rule $(\mathrm{X}=\mathrm{P}$ or $\mathrm{R})$ with a symbol $\mathrm{A}$ or $\mathrm{B}$, etc. exists in the Block $Y$, then a signal of specific parameters (characteristics) is assigned. An example of the description of the structure of a developed fact or rule is as follows:

- PA001 - means a fact from the Block A and of the number of 001 , 
- RC003 - means a rule from the Block C and of the number 003 , etc.

If the fact PA001 exists, then it means that it is a fact from the Block A and of the number 001. Thus, the following information can be found in the facts' table (Fig. 4): Object - wind turbine generator, Voltage - 20kV, Direction - WTG, Block- A (where: A-Environment and Ambient), Field - feeder cable line field, Parameter - Cut $_{\text {in }}$ wind speed, measurement type, Abb.- PWZT, parameters: average -3.5 , min. - 3.5, Unit - $\mathrm{m} / \mathrm{s}$. The implemented method of defining facts, which is above described, allowed to present facts in a simple and clear form of the table that enables to find parameters easily e.g. through characteristics or block division.

Fig. 4 shows example facts for a wind turbine generator based on the Block A - Environment and Ambient and the Block B - Grid. Fig. 5. shows facts for the substation based on the Block Q - feeder cable line filed.

Facts for all Blocks of the developed system for supervision and save usage of the wind power plant were developed in accordance with the above specified method.

\section{Conclusions}

A basic concept of the expert system depends on transferring expert's knowledge into a computer program equipped with a knowledge base, specific conclusion rules, and a user or graphical interface used for communication. All knowledge collected in the system can be used many times by many users searching for help or support. The computer gives users the best pieces of advice, according to computer's logic, and explains logic used for making conclusions. This term can be also proper to systems used in situations where a human, though they have a great knowledge on a specific field, is not able to use it optimally.

If a user of the object must take a rapid decision in a situation where there is many pieces of information but it is not confirmed, then they may act under stress, which would lead into taking wrong decisions. Thus, a machine is sometimes better than a human. When it goes for operating wind power plants where decisions must be taken fast and optimally under conditions of thousands of signals and pieces of information coming, expert systems seem to much better than humans. Thus, real time expert systems have been developed, which ensure more effective strategies of monitoring and control, where lots of data is coming e.g. monitoring of signals in nuclear power plants, space programs, interpretation of radar signals, monitoring of patients in medicine. Due to expert systems used in those fields, a number of specialists can be reduced, quality of systems can be improved, and operational cost of systems can be reduced.

\section{References}

1. L. Bedkowski, T. Dabrowski, Basic of the maintenance theory p. 2. WAT, Warsaw, p. 187,
(2006)

2. M. Bialko, The Basic properties of neural networks and hybrid expert system, Technical University of Koszalin, Koszalin, p. 341, (2000)

3. B. Buchannan, E. Shortliffe, Rule - Based expert systems. Addison - Wesley Publishing Company, p. 387 (1985)

4. S. Duer, Intelligent system of supporting the process renewal of operating characteristics in complex technical objects, Technical University of Koszalin, Koszalin, p. 242 (2012)

5. F. Hayer-Roth, D. Waterman, D. Lenat, Building expert systems. Addison - Wesley Publishing Company, p. 192 (1983)

6. W. Kacalak, M. Majewski, J. M. Zurada, Lecture Not. in Art. Int. 6114 (2010)

7. W. Kacalak, M. Majewski, Lecture Not. in Com. Sci. 7666 (2012)

8. S. Kobayashi, K. Nakamura, IEEE Expert, Oct. (2011)

9. P. Linz, R. Wang, Exploring Numerical Methods: An Introduction to Scientific Computing using Matlab. University of California, Davis, p. 172, (2003)

10. P. Linz, An Introduction to Formal Languages and Automata. University of California, Davis, (2002)

11. M. Majewski, W. Kacalak, Polish J. Env. Stu. 18, 3B (2009)

12. Z. Palkova, Warsaw Uni. of Lif. Sci. Pre. 55 (2010)

13. Z. Palkova, T. Rodny, Modeling of object-related database structures in the development of artificial irrigation system, November 2010, Slovak University of Agriculture in Nitra (2010)

14. S. Duer, Defence Sci. J. 60, 5 (2010)

15. W. Pedrycz, Fuzzy Control and fuzzy systems, John Walley End Sons, Inc, p. 432, (1993)

16. L. Pokorádi, S. Duer, International Sci. Con. on Adv. in Mech. Eng. (2016)

17. A. Rosiński, Reliability, Ris. and Saf. Theory and App., 3 (2010)

18. A. Rosiński, Advances in Saf. Rel. and Ris. Man. (2012)

19. D. Waterman, A guide to export systems, AddisonWesley Publishing Company (1986).

20. S. Duer, R. Duer, S. Mazuru, Romanian Ass. of Nonc. Tech., XX, 2 (2016)

21. S. Duer, R. Duer, Neural Com. \& App. 19, 5 (2010)

22. S. Duer, Neural Com. \& App. 1 (2012)

23. S. Duer, K. Zajkowski, I. Płocha, R. Duer, Neural Com. \& App., 22, 7 (2013)

24. Duer S., Zajkowski K.: Neural Com. \& App. 23, 7, (2013)

25. S. Duer, K. Zajkowski, R. Duer, J. Paś, Neural Com. \& App. 23, 3-4, (2013) 